\title{
Identification and epidemiological analysis of Perostrongylus falciformis infestation in Irish badgers
}

\author{
Jennifer OC. Byrne ${ }^{1 *}$, Andrew W. Byrne ${ }^{2}$, Annetta Zintl $^{3}$, Karolina Jankowska ${ }^{3}$, Emmanuel Coulange ${ }^{4}$, \\ Theo de Waal ${ }^{3}$, Grainne McCarthy ${ }^{3}$, James O'Keeffe ${ }^{5}$, Inger S. Hamnes ${ }^{6}$ and Ursula Fogarty ${ }^{1}$
}

\begin{abstract}
Background: The lungworm, Perostrongylus falciformis (fomerly known as Aelurostrongylus falciformis) has been identified in badgers (Meles meles) in Britain, the Russian Federation, Italy, Norway, Poland, Ukraine, Bosnia Herzegovina and Romania, while Aelurostrongylus pridhami has been reported from badgers in Spain.

Results: Pulmonary tissue from 1580 Irish badgers was examined and an estimated prevalence of 32.09\% (95\% Cl: 29.79-34.45\%) of this parasite was detected. Confirmation of its occurrence was made by PCR analysis on a subset of the population.

Conclusion: Infestation was widely distributed throughout the Republic of Ireland, with a trend towards higher infestation risk in western versus eastern counties. In addition males were at a higher risk of infestation than females and juveniles were at a significantly higher risk than adult badgers.
\end{abstract}

Keywords: Badger, Meles meles, Lungworm, Perostrongylus falciformis, Ireland

\section{Background}

Irish badgers are now classified with their European counterpart as Meles meles and are recognised as distinct from those found in eastern Eurasia, Japan and Crete [1]. Recent population and landscape genetic studies on the Irish badger have shown that contemporary populations have links to present-day Iberian and Scandinavian badger populations particularly in the west of Ireland, with badgers on the north-east and eastern side of the island more closely related to those in Great Britain and continental Europe [2-4]. Badgers are infected with a variety of parasites including nematodes (Uncinaria, Capillaria and Strongyloides spp), cestodes (Taenia and Mesocestoides spp) and trematodes [5, 6]. A lungworm Perostrongylus falciformis was first described in German badgers by Schlegel in 1933 [7]. Following several reclassifications, this parasite subsequently became known in the literature as Aelurostrongylus falciformis, and was included in the same genus with Aelurostrongylus abstrusus, Aelurostrongylus pridhami and

\footnotetext{
* Correspondence: jennifer.oc.byrne@gmail.com

${ }^{1}$ Irish Equine Centre, Johnstown, Naas, County Kildare, Ireland

Full list of author information is available at the end of the article
}

Aelurostrongylus fengi [8]. Recent molecular phylogenetic and morphological studies by Deak et al. [8] have reconfirmed the classification as Perostrongylus and have shown that $A$. abstrusus is distinct. P. falciformis has been identified in badgers in Britain [5], the Russian Federation [9], Italy [10], Norway [11], Poland [12], Ukraine [13], Bosnia Herzegovina [14] and Romania [8] while the species $A$. pridhami has been reported from badgers in Spain [15]. In contrast a survey of helminth infestations of the badger carried out in southwest Portugal failed to identify this parasite [16].

$P$. falicformis has an indirect life cycle with slugs and terrestrial snails serving as intermediate hosts [8]. Stage 1 (L1) larvae passed in the faeces of infected badgers penetrate the foot of the snail intermediate host where they develop to L3 larvae. Following ingestion by the definitive host, the parasite matures to the adult stage in the alveoli, alveolar ducts and terminal bronchioles. Thin-shelled eggs produced by the female worm hatch more or less immediately releasing L1 larvae which are coughed-up, swallowed and shed via the faeces. As with many wildlife parasites, infections with $P$. falciformis appear to be generally of low

(c) The Author(s). 2019 Open Access This article is distributed under the terms of the Creative Commons Attribution 4.0 International License (http://creativecommons.org/licenses/by/4.0/), which permits unrestricted use, distribution, and 
pathogenicity although rare severe and even fatal cases have been reported [8].

In 1974 badgers were identified as a wildlife host for bovine tuberculosis (bTB) in Ireland, a fact that has stimulated extensive research into the biology and ecology of this mammal $[1,17,18]$. Recent suggestions that helminth coinfecions may affect the host's immune response to concurrent TB infections [19] have further increased scientific interest in parasitic worms infecting badgers, particularly those that inhabit the same site [17]. The culling of Irish badgers as part of the national bTB eradication programme [20] has provided a unique opportunity to monitor P. falciformis in a large sample of its wildlife host. This paper confirms the presence of $P$. falciformis in Irish badgers, and presents epidemiological analysis of this lungworm infestation in Irish badgers over the period 1995-2017.

\section{Materials \& methods}

\section{Surveillance samples}

The badgers examined were those captured under a bovine TB eradication programme between 1995 and 2017, excluding 2010. These activities were coordinated through the National District Veterinary Offices organised on a county basis. Date, geographical location, age and sex of the badgers were recorded at the time of capture. Badgers were transported to the post mortem facility within $36 \mathrm{~h}$ of death, where they were stored at $0-4{ }^{\circ} \mathrm{C}$ until post mortem examination. The nature of the post mortem examination and sample collection were dictated by the requirements of the bTB eradication scheme rather than by an investigation into the occurrence/prevalence of lung- or heartworms specifically. There was no systematic bias in terms of geography, age or sex in the selection of badgers contributing to the dataset. However, lungs showing small nodular lesions on gross examination, primarily in the dorsal areas of the lung lobes were preferentially sampled because of the possibility they could be Mycobacterium bovis lesions.

\section{Identification and detection of $P$. falciformis in the badger population using histopathology}

One thousand, five hundred and-eighty badger pulmonary tissue samples were fixed in 10\% formalin, routinely processed and stained with hemotoxylin and eosin. The presence or absence of adult pulmonary parasites in the distal airways was recorded. Morphological characterisation was confirmed by experts from the Norwegian Veterinary Institute (Inger Sofie Hamnes) and the Natural History Museum, London (Eileen Harris). Histopathological examination of the lungs was carried out independently of the badger population demographics. The latter were subsequently retrieved from archival records and digitized within Microsoft Excel. With the continual reduction in the prevalence of $M$. bovis infection in badgers over the study period [21] the number of pulmonary tissue samples collected decreased particularly post 2007 (Table 1).

\section{Molecular analysis for the detection and identification of badger lungworm}

PCR analysis for molecular detection and identification of lung- and heartworms was carried out on a total of 15 badgers, captured in counties Carlow (1), Kildare (4), Kilkenny (1), Laois (1), Offaly (1), Tipperary (4) and Wexford (1) in 2017. For each animal two samples were analysed. One of these was collected by injecting $10 \mathrm{ml}$ of tap water into the upright pluck using a syringe, the other by reverse flushing of the left ventricle, pulmonary veins and pulmonary capillaries. Following centrifugation (1330 g) and DNA extraction using the QIAamp DNA mini kit, all samples were amplified using three nested PCR assays designed to amplify different regions of the nuclear rRNA genes and internal transcribed spacers. Primer sequences are listed in Table 2. All PCR assays were performed at an annealing temperature of $55^{\circ} \mathrm{C}$ under standard conditions. Amplicons were purified (High Pure PCR Product Purification Kit) and sequenced in both directions using the internal PCR primers (Eurofins Genomics).

\section{Data analysis and modelling}

All data manipulation and analysis was undertaken within Stata 14 SE. Maps were created using ArcGIS 10.3.

All lungworm results were used to assess prevalence and the overall temporal trends. Prevalence was presented with 95\% CI estimated using exact binomial CI. The outcome for each badger was modelled in a binary logit model with year fitted as i. categorical variable and ii. as a continuous linear trend. Where sample sizes were too small to estimate $95 \%$ CI for a given year (e.g. 2015 there were four observations, all were negative), these point and $\mathrm{CI}$ estimates were derived from an exact binomial distribution.

Univariable and multivariable modelling was undertaken on records where all covariate data were available. Covariate data included the county (location) where the animal was captured $(n=26)$, age-class (adult or juvenile), season (with winter: December, January, February; spring: March, April, May; summer: June, July, August

Table 1 The number of pulmonary tissue samples collected from badgers over the study period. Samples were not collected in 2010

\begin{tabular}{lllllllll}
\hline Year & 1995 & 1996 & 1997 & 1998 & 1999 & 2000 & 2001 & 2002 \\
No. of Samples & 2 & 109 & 34 & 46 & 47 & 41 & 100 & 151 \\
Year & 2003 & 2004 & 2005 & 2006 & 2007 & 2008 & 2009 & 2010 \\
No. of Samples & 192 & 157 & 124 & 338 & 131 & 2 & 2 & n/a \\
Year & 2011 & 2012 & 2013 & 2014 & 2015 & 2016 & 2017 & \\
No. of Samples & 9 & 12 & 5 & 6 & 4 & 13 & 55 & \\
\hline
\end{tabular}


Table 2 Primer sequences used to amplify fragments of the rRNA genes and internal transcribed spacers

\begin{tabular}{|c|c|c|c|}
\hline Locus (size) & Primer & Sequence & Ref \\
\hline \multirow[t]{2}{*}{$18 \mathrm{~S}$ (700 bp) } & External & $\begin{array}{l}\text { Fw: 5' AAAGATTAAGCCATGCA 3' } \\
\text { Rev.: 5'GCAGGTTCACCTACAGAT 3' }\end{array}$ & {$[22]$} \\
\hline & Nested & $\begin{array}{l}\text { Fw: 5' CGGCTCATTAGAGCAGATGTC 3' } \\
\text { Rev:: 5' TCCTCTIITATTATTCCATGATCG 3' }\end{array}$ & This study \\
\hline \multirow[t]{2}{*}{ ITS2 (548bp) } & External & $\begin{array}{l}\text { Fw: 5' TTGAACGCATAGCGTCGT 3' } \\
\text { Rev:: 5' TTAGTTTCTTITCCTCCGCT 3' }\end{array}$ & This study [23] \\
\hline & Hemi-nested & $\begin{array}{l}\text { Fw: 5' ACGTCTGGTTCAGGGTTGTT 3' } \\
\text { Rev:: 5' TTAGTTTCTIITCCTCCGCT 3' }\end{array}$ & [23] \\
\hline \multirow[t]{2}{*}{ Connecting fragment (1953 bp) } & External & $\begin{array}{l}\text { Fw: 5' GCCTTGGGCGTTAATCACTG 3' } \\
\text { Rev:: 5' TCACGATCATCAATCCATCG 3' }\end{array}$ & This study \\
\hline & Nested & $\begin{array}{l}\text { Fw: 5' AGAACAAGCGTTTGCTTGAA3' } \\
\text { Rev.: 5' GTATGACCAACAGCCGAACA3' }\end{array}$ & This study \\
\hline
\end{tabular}

and autumn: September, October, November) and sex of the animal (male/female). Logistic regression univariable models were used to investigate unadjusted relationships between infection status and each covariate respectively. A multivariable model was then developed using all variables as potential predictors of infection risk. We also investigated two-way interaction terms. Competing models were assessed using Akaike's information criterion (AIC). The alpha for significance was set to 0.05 throughout. A Hosmer-Lemeshow test was used to assess model fit (calibration), and the model discriminatory ability was assessed via the Area Under the ROC (AUC).

\section{Results}

\section{Identification and detection of $P$. falciformis in badger samples}

Adult nematodes present in terminal airways were identfied as P. falciformis based on the morphological description provided by Davidson et.al. [11] allowing for correction for the body length from micrometres to millimetres. Identification was confirmed by two independent experts. The parasites were coiled, and cylindrical in outline with a smooth cuticle. Numerous adult parasites contained larvae and larvae were often free within the adult worm as opposed to being enclosed within an egg capsule (Fig. 1). Similar observations had been made by Inger Hamnes (personal communication). The width of the L1 larvae $(10.5-11.9 \mu \mathrm{m})$ was within the range quoted for the species by Davidson et al. [11] and Deak et.al. [8]. Larvae or ova were not detected in the pulmonary arterial system. The size, pulmonary location and morphology of the parasites detected excluded Crenosoma, Capillaria, Filaroides and Angiostrongylus species.

Of the 15 badgers analysed by PCR in 2017, 12 were positive in at least 1 sample and 7 were positive in all 3 loci. All PCR products were 100\% identical to each other and to the rRNA sequences and internal transcribes space are logged in the data base for $P$. falciformis accession number (KY365435). The badgers that tested positive for $P$. falciformis in this subset were located in Kilkenny (1/1), Kildare (4/4), Laois (1/1), Offaly (1/1) and Tipperary (5/6). The badgers sampled from Carlow (0/1) and Wexford (0/ $1)$ were negative. No other lung- or heartworm species were detected using molecular techniques.

Pulmonary tissue sections positive for $P$. falciformis were never positive for typical bTB lesions. The tissue reaction to the parasite was not excessive, often minimal, and was not dominated by eosinophils (Fig. 2).

\section{Epidemiological findings}

Overall, there were 1580 badgers with a lungworm status, with an estimated prevalence of $32.09 \%$ (95\% CI: $29.79-$ $34.45 \%)$. There was significant inter-annual variability in prevalence (logistic regression with year fitted as categorical; LR $X^{2}$ (df: 18) $=46.35 ; p=0.0003$; Fig. 3). A linear trend fitted to the data suggested a non-significant decline in prevalence across the time series (OR: 0.980; $P=0.100$ ).

There were 49 records with some covariate data missing on archival data retrieval (e.g. 38 animals did not have a county assigned; 36 animals did not have a recorded sex),

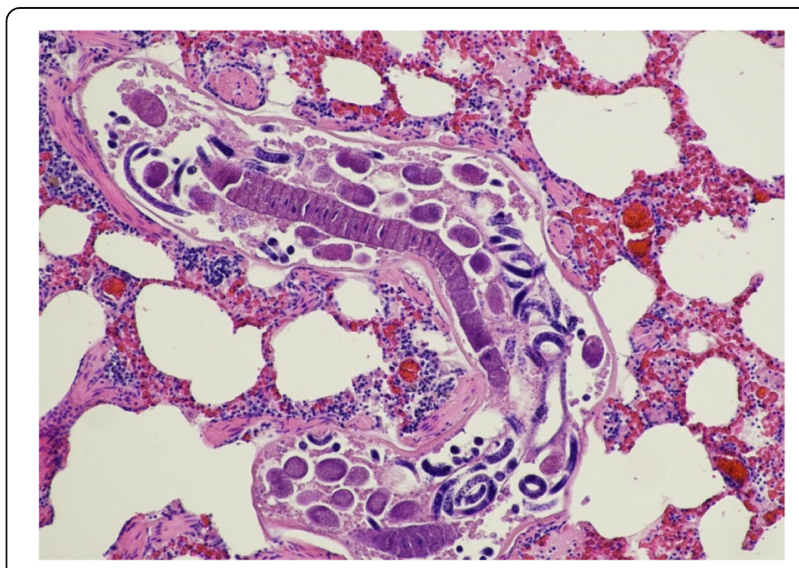

Fig. 1 Longitudinal section through an adult $P$. falciformis containing larvae ( x 100) 


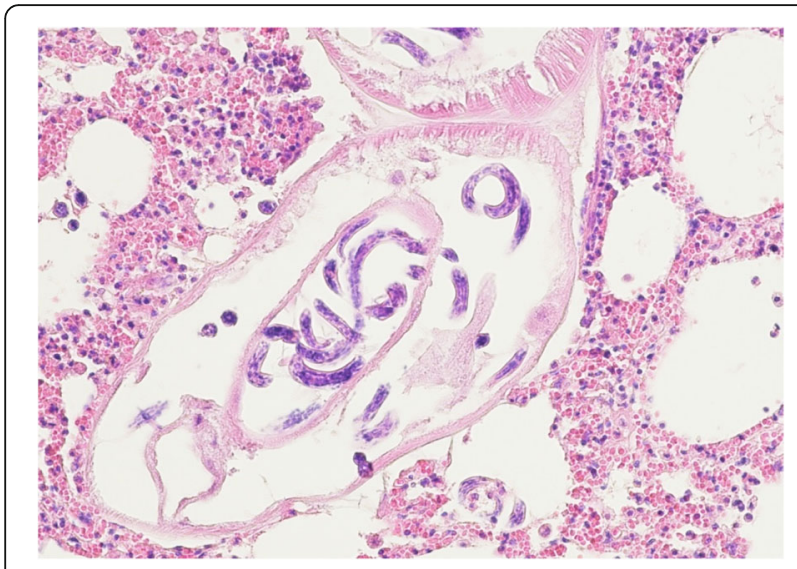

Fig. 2 Cross section through an $P$. falciformis adult female containing larvae. Tissue reaction is not marked $(\times 200)$

meaning there was a total of 1539 animal records available for modelling. There was significant variation in infestation risk across seasons, with infestation risk being higher in spring (OR: $1.443 ; P=0.003 ; 95 \% \mathrm{CI}: 1.135-1.835)$ and autumn (1.508; $P=0.008$; 95\% CI: $1.114-2.039)$ relative to animals caught in winter. There was no significant difference in risk between summer and winter $(p=0.535)$, however very few animals were captured during summer months to inform this pattern ( $n=24$ caught in summer). At the univariable level, females had a significantly lower probability of being infested compared to males (OR: $0.692 ; P=0.001 ; 95 \% \mathrm{CI}: 0.558-0.858)$, with $28.1 \%$ of females being positive relative to $36.1 \%$ of males. Adults (31.3\%) were at a significantly lower risk of infestation relative to juveniles (48.2\%) (OR: $0.491 ; P=0.002$; $95 \% \mathrm{CI}$ : $0.315-0.765)$. There was significant variation in infestation

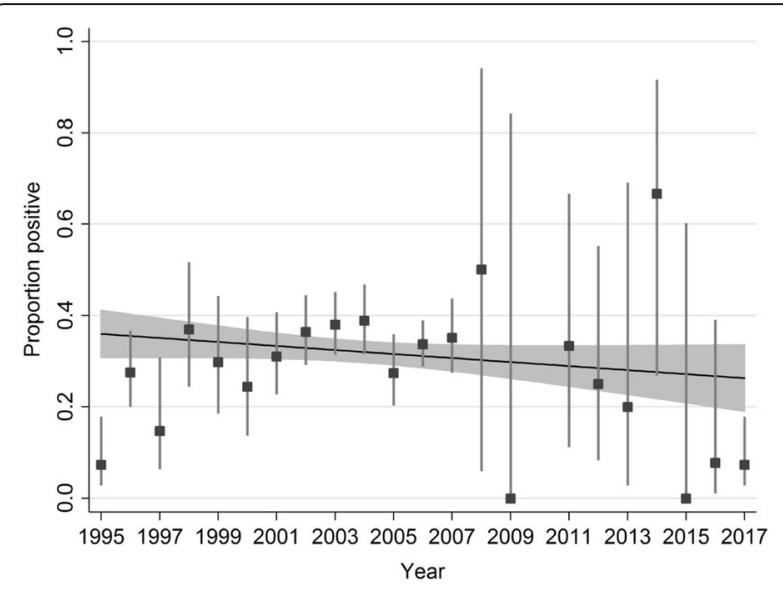

Fig. 3 The estimated probability of infestation for each year of the time series. Point estimates were estimated from a logistic regression with error bars representing $95 \% \mathrm{Cl}$, with the exception of years 2009 and 2015 which had zero prevalence, with upper 95\% $\mathrm{Cl}$ estimated using a one-tailed exact binomial $\mathrm{Cl}$. The line represents the estimated linear trend with $95 \% \mathrm{Cl}$ risk by location ( $p=0.001)$, with Mayo $(45.0 \% ; n=100)$, Laois $(42.9 \% ; n=42)$ and Offaly $(42.9 \% ; n=241)$ having the highest levels of infestation, while Meath $(9.7 \% ; n=$ $31)$, Carlow $(6.7 \% ; n=15)$ and Dublin $(0 \% ; n=10)$ had the lowest prevalence. There was no strong geographic pattern of risk across the counties of the Republic of Ireland (Fig. 4), but prevalence appeared higher overall in western counties than eastern counties (Fig. 5).

During multivariable model building we aggregated both the year ( $n=22$ years) and county ( $n=26$ counties) variables to reduce the number of parameters in the model. We fitted year as a linear trend, a quadratic form, a logarithm transform and as a binary dummy variable (preand post-2007) in alternative models. We retained the binary categorization as it had the lowest AIC across comparative models $(\triangle \mathrm{AIC}=10)$. Given the pattern of prevalence across counties, we fitted a binary model for eastern (Dublin, Louth, Monaghan, Wicklow, Carlow, Kilkenny, Wexford, Waterford, Meath, Westmeath, Longford, Cavan Offaly and Laois) and western (Donegal, Sligo, Mayo, Galway, Roscommon, Clare, Leitrim, Limerick, Cork and Kerry) counties (see supplementary material for map). The final multivariable model is presented in Table 3; the AIC of the final model was 1886, with the next best model having an AIC of 1890. The AUC of the model suggested fair discriminatory ability at 0.62 ; there was no evidence for misspecification (calibration) in the model fit (Hosmer-Lemeshow test: $p=0.855)$. Overall, there was evidence of decreased risk for adult, female badgers, captured after 2007, relative to juvenile, males and badgers captured during or prior to 2007. Furthermore, there was increased risk of observing infestation in Spring and Autumn relative to Winter months, and increased risk in western counties relative to eastern and midland counties (Table 3).

\section{Discussion}

Byrne and colleagues [17] were the first to report the presence of $P$. falciformis (still referred to as A. falciformis) in Irish badgers. Their study is chiefly based on the morphological identification of adult worms and larvae detected in heart, lungs and faecal samples. While this is considered a reliable method for the identifying adult worms first stage larvae of P.falciformis are morphologically very similar to those of Angiostronglyus species with which they may be confused [11]. The recent publication by Deak et al. [8] has provided a detailed morphiological description of the larvae and adults of P. falciformis as well as genetic information. The morphological and molecular data reported in our study agree with their findings and confirm the presence of $P$. falciformis in Irish badgers. We also provide a model of the geographic distribution $P$. falciformis in Ireland. The same species of lungworm has been reported from badgers in many parts of Europe and 


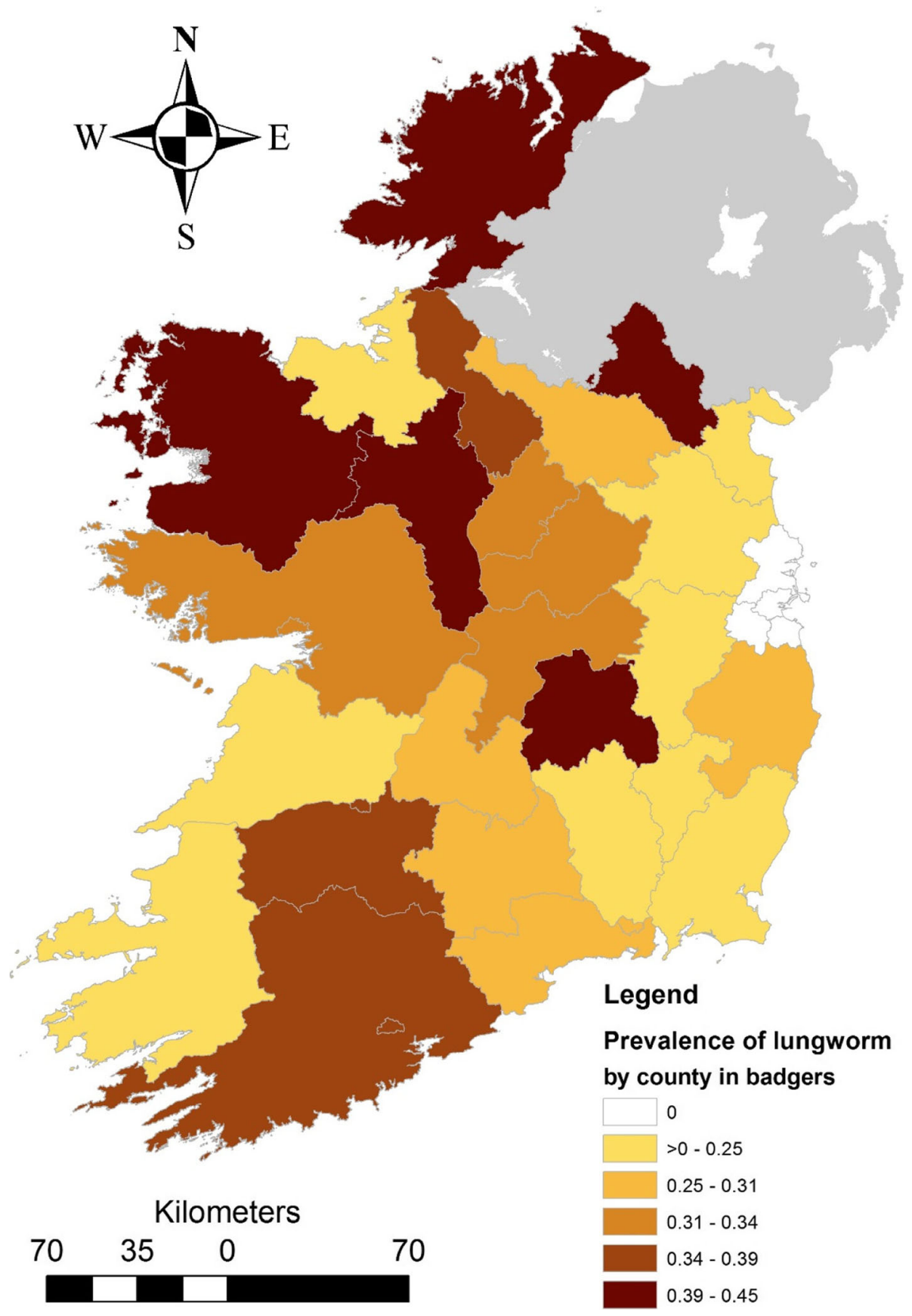

Fig. 4 Choropleth map of the variation in prevalence of $P$. falciformis at County level across the Republic of Ireland. Note, Northern Ireland (greyed area) was not sampled for the current study

Russia $(10-12 ; 18-21 ; 28)$. In contrast, a different species, A. pridhami has been identified in Spanish badgers [15] (even though the identification is disputed by some [8]). This is interesting, given the genetic association between Spanish and Irish badgers. A. pridhami primarily infests American mink, and has been identified in invasive American mink in Spain. Morphological and PCR analysis of additional badgers, particularly from the west and south-west of Ireland are required to establish whether there are other badger lungworm species present in Ireland.

In the present study no additional lung- or heartworms were detected. The reason for this may have been that we focused chiefly on the dorsal areas of the lung lobes, which may have precluded detection of other parasite species. Byrne et al. [17] reported Crenosoma spp infestation at a prevalence of $1 \%$ in their Irish badger sample. Several 


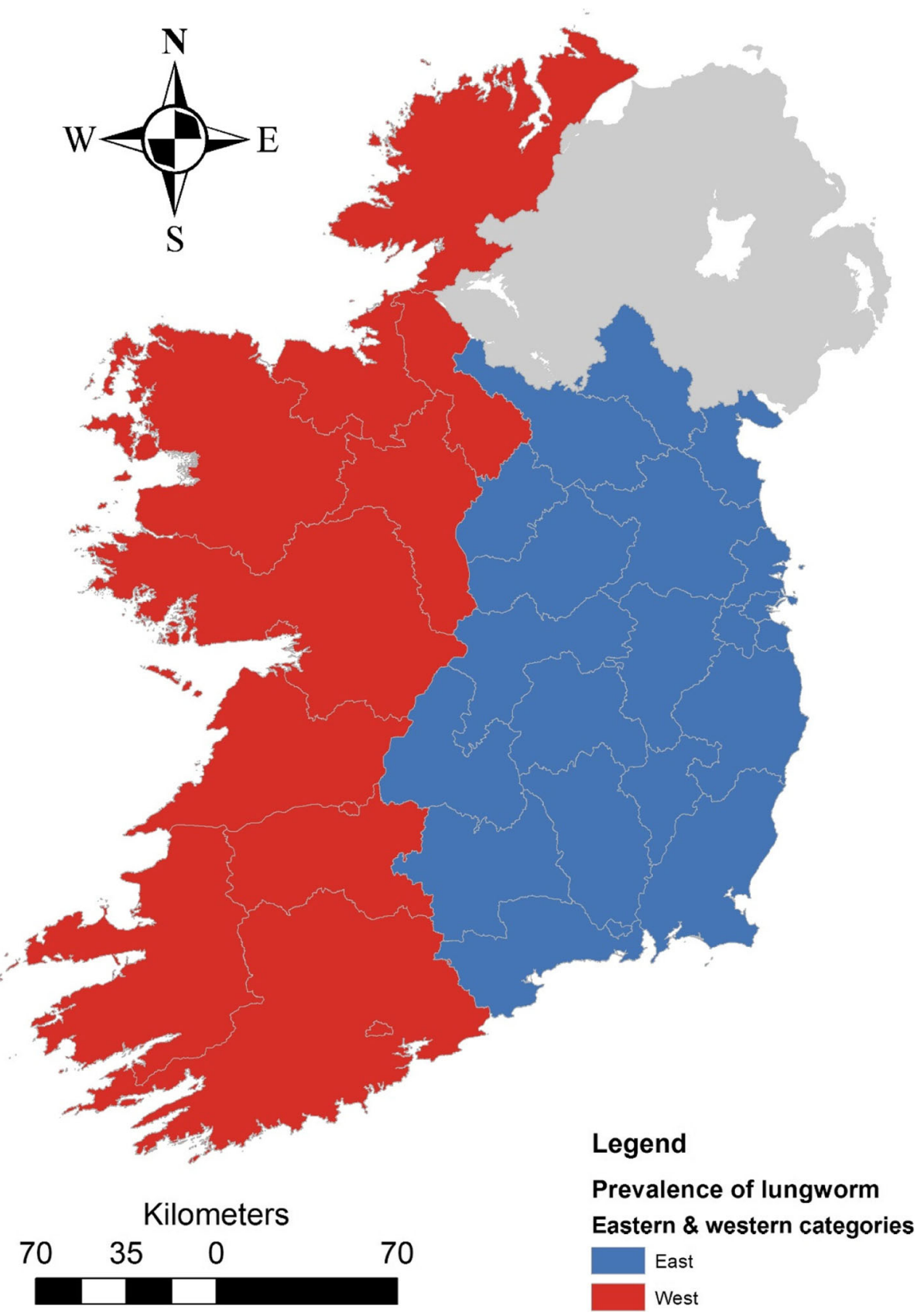

Fig. 5 Supplementary material: Eastern versus western counties categorization used in final multivariable model

European publications have also reported both Angiostrongylus vasorum and Angiostrongylus daskalovi in badgers [6, $10,15,24,25]$. Neither parasite was detected in this study or by Byrne et al. [17] even though $A$. vasorum is an important parasite of dogs in Ireland and was detected in 39.9\% of Irish red foxes (Vulpes vulpes) in a recent study [26]. Foxes and badgers can co-habit in badger sets and would have a similar environmental exposure $[1,27]$. It is also noteworthy that trematodes or cestodes were not identified by Byrne et al. [17], despite being specifically looked for.
The prevalence of $P$. falciformis varies between studies. In Britain during routine examination of badgers for bTB just 1 out of 118 badgers was recorded as being infested with $P$. falciformis [18]. Other studies showed higher prevalence rates. In an Italian study 53\% (10/19) badgers were found to be infested [10]; in a Norwegian study 56\% (5/9) [11]; in Poland 22\% (2/9) [12]. In Bosnia Herzegovina 100\% (1/1) [14], Romania 33\% (9/27) [8] and Germany $75 \%(3 / 4)$ of badgers were infested [8]. A study from Spain suggested that $6.4 \%$ of 47 badgers were 
Table 3 Multivariable logistic model assessing the relationship between badger lungworm infestation risk and animal, temporal, and spatial characteristics

\begin{tabular}{|c|c|c|c|c|c|c|}
\hline Outcome: Infection status & & Odds Ratio & Std. Err. & $P>z$ & Lower 95\%Cl & Upper $95 \% \mathrm{Cl}$ \\
\hline \multirow[t]{2}{*}{ Age-class } & Juvenile & 1.000 & & & & \\
\hline & Adult & 0.456 & 0.107 & 0.001 & 0.288 & 0.722 \\
\hline \multirow[t]{2}{*}{ Sex } & Male & 1.000 & & & & \\
\hline & Female & 0.659 & 0.074 & 0.000 & 0.528 & 0.822 \\
\hline \multirow[t]{2}{*}{ Year } & Year $\leq 2007$ & 1.000 & & & & \\
\hline & Year > 2007 & 0.338 & 0.097 & 0.000 & 0.192 & 0.595 \\
\hline \multirow[t]{4}{*}{ Season } & Winter & 1.000 & & & & \\
\hline & Spring & 1.497 & 0.188 & 0.001 & 1.171 & 1.914 \\
\hline & Summer & 0.739 & 0.393 & 0.570 & 0.261 & 2.095 \\
\hline & Autumn & 1.706 & 0.274 & 0.001 & 1.245 & 2.336 \\
\hline \multirow[t]{3}{*}{ Location } & Eastern county & 1.000 & & & & \\
\hline & Western county & 1.385 & 0.157 & 0.004 & 1.110 & 1.729 \\
\hline & Constant & 0.870 & 0.220 & 0.580 & 0.530 & 1.427 \\
\hline
\end{tabular}

infested with A. pridhami [15], while in a sample of 163 badgers in Portugal no lungworm were detected [26].

In this study, an estimated prevalence of $32.09 \%(95 \%$ CI: 29.79-34.45\%) was found, with some evidence of a declining prevalence over the sampling period (1995 to 2017). While this may be a real decrease it could also be due to the reduced sampling protocol as described above. Byrne et al. [17] detected a $20 \%$ prevalence of $P$. falciformis in 289 Irish badgers between December 2016 and October 2017. It is also important to note that PCR analysis indicated a much higher infection rate (around 80\%), however this figure is based on a very small subsample.

$P$. falciformis require gastropod intermediate hosts such as slugs and snails to complete their life cycle [8]. It is possible that mice and other small vertebrates for example frogs may act as auxiliary hosts, as for A pridhami. Ireland would be deemed favourable for the survival of slugs, snails and frogs. In fact dietary investigation by Cleary [18] on a subsection of this population showed a high intake of frogs by the Irish badger which may increase the exposure and possible prevalence of this parasite.

We found significant county level variation in infestation risk, and a trend toward higher infestation rates in the western part of Ireland relative to the eastern counties, which could be related to weather conditions, as western counties have significantly higher rainfall and probably also a greater availability of intermediate/ axillary hosts than eastern counties.

During the present study, we found that males exhibited higher risk of infestation relative to females, and juveniles relative to adult badgers. The Spanish study noted no sexor age-specific differences in prevalence rates with regard to A. pridhami [15]. The capture method in Ireland favours adult badgers [28], and consequently there was a lower number of juveniles included in this study. However, we still found a significantly higher prevalence in young badgers suggesting an age-prevalence relationship, perhaps indicating that mature animals develop a degree of resistance. P. falciformis females are ovoviviparous and lay embryonated eggs. Embryonated eggs are illustrated in the studies by Demiasszkiewicz et al. [12] and Deak et. Al. [8]. Free larvae within the adult worm have also been observed by Inger Hamnes (personal communication) and possibly represent hatched larvae in the post sampling period. It is interesting to note that in this study the badger immune reaction to $P$. falciformis could not be deemed excessive and was not dominated by eosinophils. Moreover no concurrent infections with $M$. bovis were observed in the sections examined. Similarly no association was found by Byrne et al. [17] between TB status and P. falciformis infestation. Parasitic infestations have been associated with modification of the host immune response to concurrent bacterial infections and allergic reactions, and there is on-going research into parasite -bTB coinfestation dynamics $[19,29]$.

While pathological studies have described and attributed serious pulmonary pathology and verminous pneumonia to the presence of this parasite $[8,14]$, this would not appear to be the case in this population. Coughing is a feature of heavy experimental infestations [8]. It is interesting to note that field operatives never report coughing in captured badgers. However, it is difficult to assign clinical signs to a wildlife host, as they are not normally seen in a clinical context.

\section{Conclusion}

During the present study we have confirmed the presence of $P$. falciformis in Irish badgers using comparative 
morphological investigation and PCR. A large, long-term surveillance dataset indicates that lungworm infestation in badgers in Ireland is prevalent in the population at a level of $32.09 \%$ (95\% CI: 29.79-34.45\%) and widely distributed geographically. The analysis suggested significant geographical variation in infestation risk across counties, with a trend towards higher risk in western versus eastern counties of Ireland. At the animal level, males were at higher risk of infestation than females, and juveniles were at significantly higher risk of infestation than adult badgers. The data also contributes to an understanding of the complexities of the host/parasite interaction.

\section{Acknowledgements}

We would like to thank Sarah Gorey and Noel Buckley of the Irish Equine Centre for all of their help with archival data retrieval.

\section{Authors' contributions}

JOK is responsible for the strategic badger culling programme conducted in bovine tuberculosis endemic regions by DAFM, which made this study possible. Collection of the pulmonary tissue samples was carried out by Ursula Fogarty. JOCB, ISH and UF were responsible for the morphological identification of $P$. falciformis. Histopathological examination of the samples for the detection of $P$. falciformis and the documentation of the results and epidemiological data in excel format was carried out by Jennifer OC Byrne. Andrew W. Byrne analysed the morphological and epidemiological data. AZ, $\mathrm{K}, \mathrm{EC}, \mathrm{TW}$ and GMC carried out PCR analysis on a subset of the samples collected.

\section{Funding}

The sample provision was facilitated by the DAFM.

\section{Availability of data and materials}

Animals were not specifically killed for this study. The animals were provided by the Irish Department of Agriculture, Food and the Marine (DAFM).

\section{Ethics approval}

Badgers were provided by the Irish Department of Agriculture, Food and the Marine (DAFM) from the strategic culling programme conducted in bovine tuberculosis endemic regions by DAFM, under a National Parks and Wildlife Services license. No animals were killed specifically for the purposes of this study.

\section{Consent for publication}

Not applicable.

\section{Competing interests}

The authors declare that they have no competing interests.

\section{Author details \\ ${ }^{1}$ Irish Equine Centre, Johnstown, Naas, County Kildare, Ireland. ${ }^{2}$ Veterinary Sciences Division, Agri-Food and Biosciences Institute (AFBI), Stoney Road, Belfast BT4 3SD, Northern Ireland. ${ }^{3}$ UCD Veterinary Sciences Centre, University College Dublin, Dublin, Ireland. ${ }^{4}$ Paul Sabatier University, Toulouse, France. ${ }^{5}$ Department of Agriculture, Food and the Marine (DAFM), Dublin, Republic of Ireland. ${ }^{6}$ Section of Parasitology, Norwegian Veterinary Institute, Sentrum, NO-0106 Oslo, Norway.}

Received: 19 November 2018 Accepted: 24 June 2019

Published online: 09 July 2019

\section{References}

1. Byrne AW, Sleeman PD, O'Keeffe J, Davenport J. The ecology of the European badger (Meles meles) in Ireland - a review. BioE ProcRIA. 2012; 112B(1):105-32. https://doi.org/10.2307/23188067.
2. Allen RA, Guerrero J, Byrne WA, Lavery J, Presho E, Kelly G, Courcier AE, O'Keeffe J, Fogarty U, O'Meara BD, Ensing D, McCormick C, Biek R, Skuce AR. The population and landscape genetics of the European badger (Meles meles) in Ireland. Animal genetics and disease conference, Wellcome genome campus, Hinxton, UK; 2017.

3. Guerrero J, Byrne AW, Lavery J, Presho E, Kelly G, Courcier EA, O'Keeffe J, Fogarty U, O'Meara DB, Ensing D, McCormick C. The population and landscape genetics of the European badger (Meles meles) in Ireland. Ecol Evol. 2018;8(20):10233-46 https://doi.org/10.1002/ece3.4498.

4. O'Meara DB, Edwards CJ, Sleeman D, Cross TF, Statham MJ, McDowell JR, Dillane E, Coughlan JP, O'Leary D, O'Reilly C, Bradley DG. Genetic structure of Eurasian badgers Meles meles (Carnivora: Mustelidae) and the colonization history of Ireland. Biol J Linnean Soc. 2012;106(4):893-909 https://doi.org/10.1111/j.1095-8312.2012.01927.x.

5. Jones GW, Neal C, Harris EA. The helminth parasites of the badger (Meles meles) in Cornwall. Mammal Rev. 1980;10:163-4.

6. Millan J, Sevilla I, Gerrikagoita X, Garcia-Perez AL, Barral M. Helminth parasites of the Eurasian badger (Meles meles) in the Basque Country (Spain). Eur J Wildlife Res. 2004;50(1):37-40.

7. Schlegel M. Die Lungenwurmseuche beim Dachs (the lungworm epidemic in the badger). Dtsch Tierarztl Wochenschr. 1933;22:341-4.

8. Deak G, Mihalca AD, Hirzmann J, Colella V, Tabaran FA, Cavalera MA, Brudasca FG, Bauer C, Ionica AM, Alic A, Otranto D, Ghermann CM. Validity of genus Perostrongylus Schlegel, 1934 with new data on Perostrongylus falciformis (Schlegel, 1933) in Eurasian badgers, Meles meles (Linnaeus, 1758): distribution, life-cycle and pathology. Parasit Vectors. 2018;11(568) https:// doi.org/10.1186/s13071-018-3124-X.

9. Kontrimavichus VL, Delyamure SL, Boev SN. Metastrongyloids of domestic and wild animals. Osnovy Nematodologii vol. 26, Akademiia Nauk SSSR, Moskva (English translation) 1985; published for the United States Dept. of agriculture and the National Science Foundation, Washington, D.C., by Amerind Pub. Co., New Delhi India).

10. Magi M, Banchi C, Barchetti A, Guberti V. The parasites of the badger (Meles meles) in the north of Mugello (Florence, Italy). Parassitologia. 1999;41:533-6.

11. Davidson KR, Handeland K, Gjerde B. The first report of Aelurostrongylus falciformis in Norwegian badgers (Meles meles). Acta Vet Scand. 2006;13:4851. https://doi.org/10.1186/1751-0147-48-6.

12. Demiaszkiewicz WA, Filip JK, Pyziel MA. The first reports of Aelurostrongylus falciformis (Schlegel, 1933) (Nematoda, Metastrongloidea) in badger (Meles meles) in Poland. Ann Parasitol. 2017;63(2):117-20. https://doi.org/10.17420/ ap6302.94.

13. Kadenatsii AN. Helminthofauna of mammals of Crimea and experience of recovery of domestic animals from basic helminthiases: Helminthol. Laboratory of Acad. Sciences of the USSR. Chair of parasitology of Omsk vet. In-ta; 1957. p. 137.

14. Stevanovic O, Trbojevic I, Nikolic S, Santrac V. The first reported case of advanced aulerurostrongylosis in Eurasian badger (Meles meles, L. 1758) in Bosnia and Herzegovina: histopathological and parasitological findings. Parasitol Res. 2018;117:3029-32. https://doi.org/10.1007/s00436-018-5984-6.

15. Torres J, Miquel J, Motje M. Helminth parasites of the Eurasian badger (Meles meles) in Spain: a biogeographic approach. Parasitol Res. 2001;87(4):259-63.

16. Rosalino LM, Torres J, Santos-Reis M. A survey of helminth infection eurasian badgers (Meles meles) in relation to their foraging behaviour in am Mediterranean environment in Southwest Portugal. Eur J Wildlife Res. 2006; 52(3):202-6. https://doi.org/10.1007/s10344-006-0033-7.

17. Byrne RL, Fogarty U, Marples N, Holland CV. A comparison of helminth infections as assessed through coprological analysis and adult worm burdens in a wild host. IJP Parasit Wildlife. 2018;7(3):439-44. https://doi.org/ 10.1016/j.jppaw.2018.11.003.

18. Cleary GP. The diet of the Eurasian badger (Meles meles) in the Republic of Ireland: PhD Thesis, Trinity College Dublin; 2007.

19. Claridge J, Diggle P, McCann CM, Mulcahy G, Flynn R, McNair J, Strain S, Welsh M, Baylis M, Williams DJ. Fasciola hepatica is associated with the failure to detect bovine tuberculosis in dairy cattle. Nat Commun. 2012;3:853.

20. Noonan N, Sheane WD, Haper LR, Ryan PJ. Wildlife as a possible reservoir of bovine TB. IVJ. 1975;29:1-5.

21. European Commission Health \& Consumers Directorate General, Report on the Task Force Meeting of the Bovine Tuberculosis Subgroup, 5-6 March 2014, Dublin (Backweston), Ireland. Ref. Ares 2014; 1515766 - 13/5/2014.

22. Bertelson MF, Meyland-Smith F, Willesen JL, Jefferies R, Morgan ER, Monrad J. Diversity and prevalence metastrongyloid nematodes infecting the red 
panda (Ailurus fulgent) in European zoos. Vet Parasitol. 2010;172(3-4):299304. https://doi.org/10.1016/j.vetpar.2010.04.043.

23. Gasser RB, Chilton NB, Hoste H, Beveridge I. Rapid sequencing of rDNA from single worms and eggs of parasitic helminths. Nucleic Acids Res. 2010; 21(10):2525-6

24. Gherman CM, Deak G, Matei IA, Ionica AM, D'Amico G, Taulescu M, BarbuTudoran L, Sarmasi A. Mihalca AD, Cozma V. a rare cardiopulmonary parasite of the European badge, Meles meles: first description of the larvae, ulrastructure, pathological changes and molecular identification of Angiostrongylus daskalovi Janchev and Genov 1980. Parasit.Vectors. 2016;9(1):423. https://doi.org/10.1186/ s13071-016-1718-8

25. Janchev J, Genov T. Angiostrongylus daskalovi spp. (Nematoda: Filaroididae) from Mustelidae in Bulgaria. Helminthologia. 1988;252:81-8.

26. McCarthy G, Ferrand M, De Waal T, Zintl A, McGrath G, Byrne W, O'Neill EJ. Geographical distribution of Angiostrongylus vasorum in foxes (Vulpes vulpes) in the Republic of Ireland. Parasitology. 2016;143(5):588-93. https://doi.org/ 10.1017/S0031182016000032.

27. Aziz NA, Daly E, Allen S, Rowson B, Greig C, Forman D, Morgan RE. Distribution of Angiostrongylus vasorum and its gastropod intermediate hosts along the rural - urban gradient in two cities in the United Kingdom, using real time PCR. Parasit Vectors. 2016;9:56-69. https://doi.org/10.1186/s13071-016-1338-3.

28. Byrne AW, O'Keeffe J, Green S, Sleeman DP, Corner LA, Gormley E, Murphy D, Martin SW, Davenport J. Population estimation and trappability of the European badger (Meles meles): implications for tuberculosis management. PLoS One. 2012;7(12):e50807.

29. Byrne AW, Graham J, Brown C, Donaghy A, Guelbenzu-Gonzalo M, McNair J, Skuce RA, Allen A, McDowell SW. Modelling the variation in skin-test tuberculin reactions, post-mortem lesion counts and case pathology in tuberculosisexposed cattle: effects of animal characteristics, histories and co-infection. Transbound Emerg Dis. 2018;65(3):844-58. https://doi.org/10.1111/tbed.12814.

\section{Publisher's Note}

Springer Nature remains neutral with regard to jurisdictional claims in published maps and institutional affiliations.

Ready to submit your research? Choose BMC and benefit from:

- fast, convenient online submission

- thorough peer review by experienced researchers in your field

- rapid publication on acceptance

- support for research data, including large and complex data types

- gold Open Access which fosters wider collaboration and increased citations

- maximum visibility for your research: over $100 \mathrm{M}$ website views per year

At $\mathrm{BMC}$, research is always in progress.

Learn more biomedcentral.com/submissions 